\title{
EXTENSIVE CONGENITAL MALFORMATION OF THE SKIN
}

\author{
BY \\ LINTON SNAITH, M.D., M.S., F.R.C.S., M.R.C.O.G. \\ Maternity Officer, City of Newcastle-on-Tyne; Obstetrician and Gynae- \\ cologist, Newcastle General Hospital; Late Obstetric Surgeon, North \\ Middlesex Hospital.
}

The following case is of some interest on account of the unusual extent of the deformity produced, and the difficulty of assigning to it any adequate explanation. The accompanying photographs illustrate well the condition seen (fig. 1 and 2).

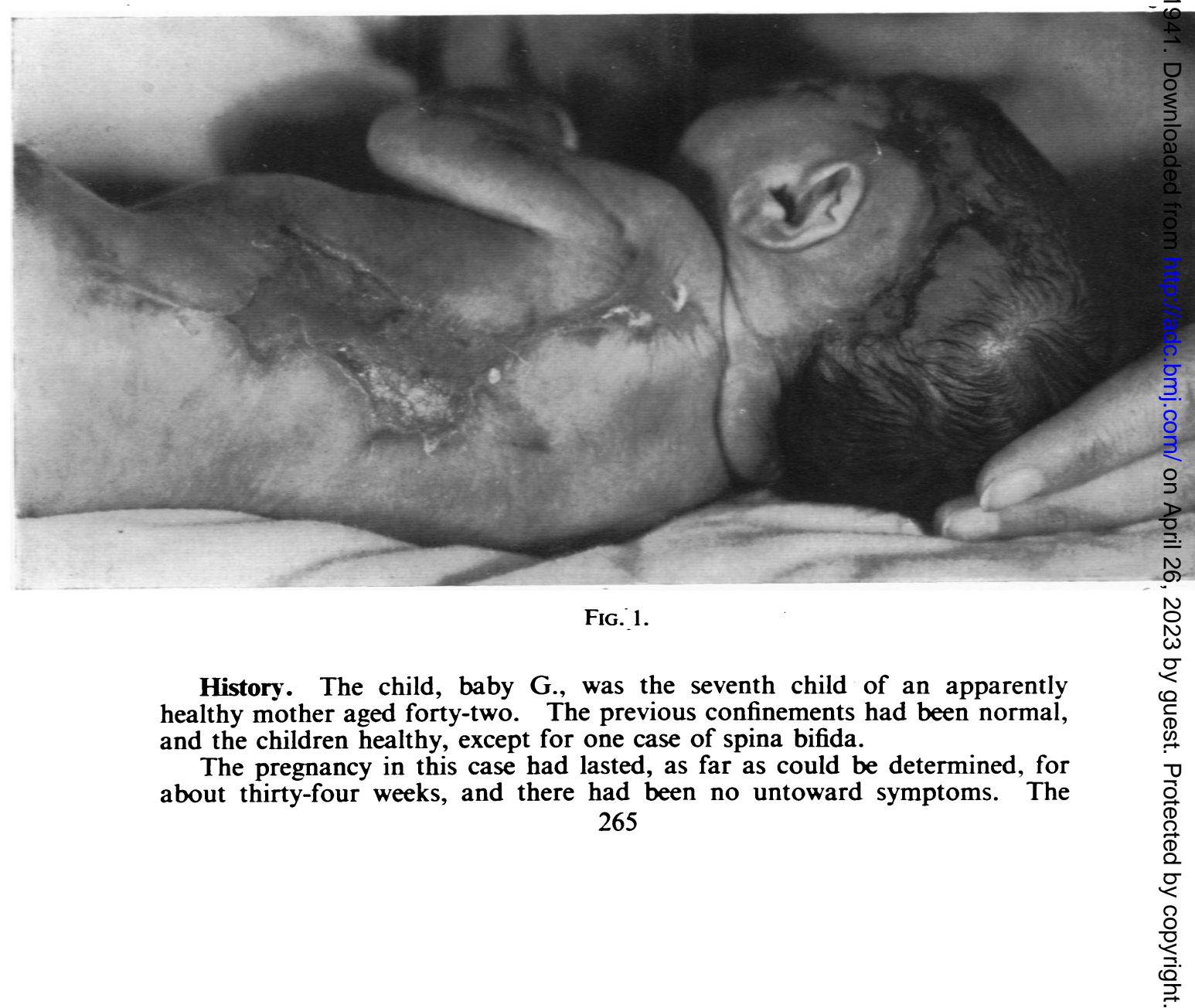


membranes ruptured spontaneously on December 1, 1938, but pains did not begin until nearly seven days later, on December 7, at 9 p.m. After about twelve hours, pains became irregular, so the attendant midwife gave a hot douche, following which contractions increased, and the child was born a few minutes later, at 9.30 a.m. on December 8 . The third stage was prolonged and attempts at expression having failed, the doctor who had been summoned sent the patient into hospital with the baby. On admission the mother was in fair condition, though slightly shocked, and there had been no bleeding : morphine was given, and after a few hours rest the placenta was removed manually.

Physical examination. The child appeared to be of thirty-four to thirty-six

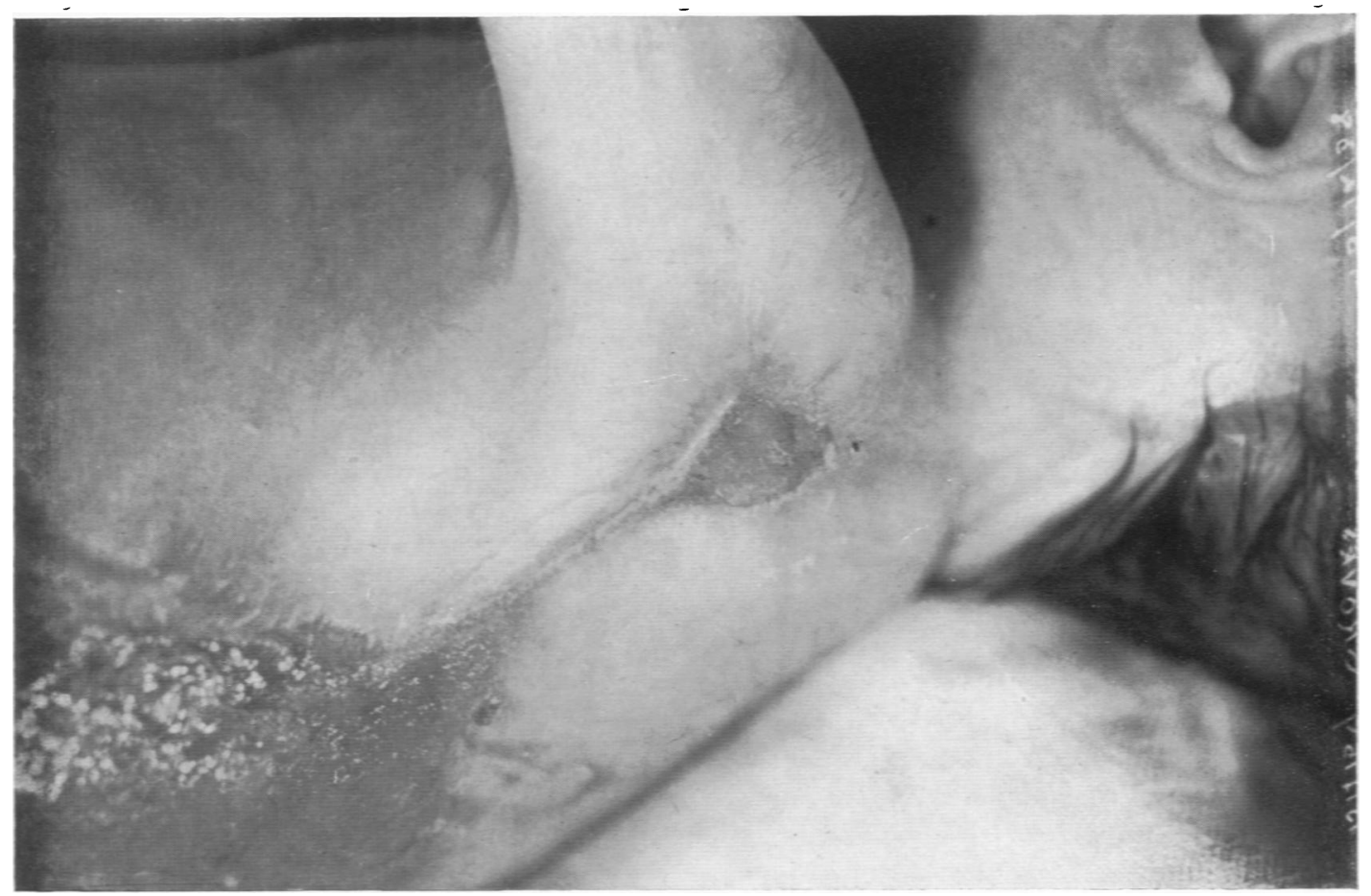

FIG. 2.

weeks' development; length $17 \frac{1}{2}$ inches; weight $3 \mathrm{lb} .6 \mathrm{oz}$; skull 11 inches in circumference. The child was quite lively, and in good condition, but had a slight talipes equinus deformity in the right foot. The most striking feature was a large linear marking of the skin extending in a hook shape from above and in front of the left ear, behind the pinna, down the neck and left side of the body to the thigh, as far as the knee, with a secondary mark extending on to the outer side of the left arm. In places this linear mark broadened to about an inch, and its depth varied from a slight superficial erythema to actual ulceration of the skin. In places there was apparent granulation tissue and some well-defined fibrous-tissue formation, which appeared to have contracted on the neck; the whole condition resembled very closely a healing second and third degree burn.

Progress. The mother made excellent progress and produced adequate 
supplies of milk, on which the child gained weight satisfactorily. After a fortnight, as the mother had many household cares, she was allowed to go home, and attended twice daily for expression of milk. The Wassermann reaction of the mother's blood was negative. Performance of the test on the child was, rather unfortunately, postponed, as the child was discharged from hospital quite healthy after a month, but returned ten days later with broncho-pneumonia, and died.

The progress of the malformation exactly followed that of a burn with rapid healing under a paraffin dressing. Moderately severe scar contracture occurred, especially in the neck, and produced before death a mild degree of torticollis.

Post-mortem examination on the child showed broncho-pneumonia but no other lesion, and the healing scar presented no abnormality, consisting of simple fibrous tissue, with a moderate round cell infiltration, and no sign of any of the granulomas, or of unusual blood-vessel formation or pigmentation.

Careful investigation was made into the history of the whole pregnancy and confinement. The mother strongly and repeatedly denied any interference whatever at any time, and apart from the douche given by the nurse shortly before birth, there appears to have been no possibility of trauma.

\section{Discussion}

The cause of congenital malformations such as talipes, intrauterine amputations of fingers and ears, and 'dimpling' of the skin has been widely discussed. Browne (1936) has produced considerable evidence in support of intra-uterine pressure as a factor in most of the common malformations, and has suggested (personal communication) that lack of liquor amnii with resulting pressure and abrasion may be responsible for a malformation such as that described here. This case, however, presents several unusual features. The deformity was extensive, and indeed I can find no record of any other case with an injury of the skin of any comparable extent. The involvement of the hollow of the neck and the duplication on both arm and body of the same appearance are difficult to explain by a pressure theory. If the latter were the cause, it would have been expected that only the more prominent and therefore the most exposed parts would show the greatest involvement, whereas the neck hollow appears to have suffered the most damage and also the earliest, as healing was most marked here. The extent of the formation of fibrous tissue at birth suggested that the healing had been going on for a greater period than seven days (during which time the membranes had been ruptured), though it is recognized that this is a doubtful criterion, as healing in utero is probably greatly in excess of the normal. The maternal Wassermann reaction was negative, and though the factor of recent pregnancy might modify the value of this, I consider that a syphilitic history can be excluded when this negative is considered in conjunction with the obstetric history, the appearances of the child, and the absence of histological signs of syphilis in the scar at post-mortem.

It appears possible that such an injury might be produced by an attempt to procure abortion by the intra-uterine use of an instrument early in pregnancy: before flexion of the head for example, a linear injury might result, later becoming curved as development proceeded.

Such a theory, however, presents many objections. It seems unlikely that use of an instrument at a later date, after the formation of the amniotic sac, could injure the foetus without also rupturing the membranes and producing 
abortion. It is possible that such an attempt may have been made ten days or so before birth, but some injury to the mother with such an extensive lesion in the child would have been expected.

Against the possibility of injury must be set the fact that the mother appeared to be a decent honest person, who was most distressed by the appearance of the child, and persistent in her denials of any interference either by herself or others.

\section{Summary}

1. A case is described of a widespread congenital skin malformation.

2. Various possible causes are discussed.

3. It is shown that injury by an instrument, or pressure due to deficient liquor, as a cause for the deformity, is not fully consistent with all the facts.

\section{REFERENCES}

Browne, D. (1936). Proc. roy. Soc. Med., 29, 1409. 